\section{IMAM 2017}

\section{The $17^{\text {th }}$ International Congress on Maritime Transportation and Harvesting of Sea Resources}

The $17^{\text {th }}$ International Congress of the International Maritime Association of the Mediterranean (IMAM) was held in Lisbon, Portugal between $9^{\text {th }}$ and $11^{\text {th }}$ October 2017 under the topic Maritime Transportation and Harvesting of Sea Resources. This congress has nearly a 40-year history since the first Congress of the International Maritime Association of East Mediterranean (IMAEM) held in Istanbul in 1978. After 1990, the name of the Association, and the Congress, was changed to IMAM.

IMAM is a voluntary organization that was initially established in 1974. It is an association of academic and professional institutions who aim to contribute to the efficient, economic, and safe operation of ships, offshore and coastal structures, and port infrastructures. The goal is to promote the advancement of the use of the seas and coastal waters for a sustainable development of the societies. Members are from countries neighbouring the Mediterranean.

The Congress was opened by IMAM 2017 Congress Chairman and IMAM Vice-president Prof. Carlos Guedes Soares from the Instituto Superior Técnico (Portugal) and by IMAM President Prof. Jasna PrpićOršic from the University of Rijeka (Croatia).

The Congress is addressed to individuals from industry, research organizations, universities, government agencies, certifying authorities as well as designers, operators and owners who contribute to improved knowledge about the marine environment, ship and offshore design, building and maintenance technology, maritime transportation and port operation and exploitation, offshore oil and gas exploitation, nautical activities, and marinas, fisheries and aquaculture, maritime safety and protection of the environment.

The preparation of the Conference Proceedings and logistic organization of the IMAM 2017 Congress was done by the Centre for Marine Technology and Ocean Engineering (CENTEC). The Conference Proceedings were published as a book and in USB format, a publication of CRC Taylor \& Francis Group. About 300 abstracts were submitted but after the reviewing process 155 papers have been accepted and included in the Conference Proceedings.

IMAM 2017 incorporated:

- International Workshop on Nautical Traffic Models that covered: general aspects of maritime risk and safety, maritime traffic simulation technologies, maritime traffic engineering, human factors, and related field,

- special sessions in honour of Prof. Peter Kolev, Prof. Vedran Žanić and Prof. Giovanni Benvenuto who had been active in IMAM and have retired recently.

On the last day of the IMAM Congress General Assembly meeting was held. It was decided that IMAM Congress mission will continue and that the next congress will be held in Varna, Bulgaria, in 2019.

\section{Vlatka Stupalo, Ph.D. University of Zagreb \\ Faculty of Transport and Traffic Sciences}

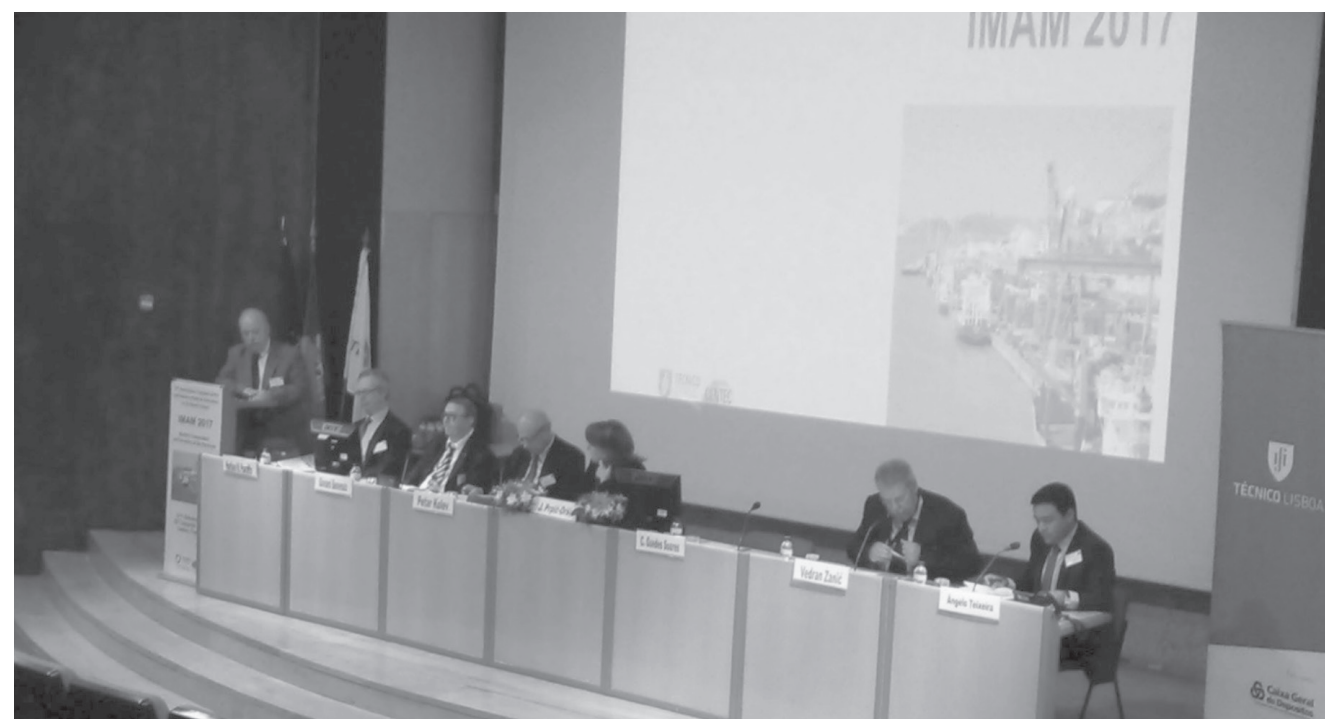

Figure 1 - IMAM 2017 Opening session

From left to right: Carlos Guedes Soares, Harilaos N. Psaraftis, Giovanni Benvenuto, Petar Kolev, Jasna Prpić-Oršić, Vedran Žanić, Ângelo Teixeira

Source: IMAM 2017 Conference Secretariat 